Author copy

Crina Damsa \& Hanni Muukkonen (2020) Conceptualising pedagogical designs for learning through object-oriented collaboration in higher education, Research Papers in

Education, 35:1, 82-104, DOI: 10.1080/02671522.2019.1677751

\title{
Conceptualising pedagogical designs for learning through object-oriented collaboration in higher education
}

\author{
Crina Damsa \& Hanni Muukkonen
}

\begin{abstract}
This paper elaborates on the notion of object-oriented collaborative learning by building on empirical material from two case studies in higher education. Prior empirical findings show how knowledge objects are evolving entities, shaped by the interactions between participants, and how students learn from engaging in knowledge practice that involves different activities with knowledge objects. However, the pedagogy of teaching and learning with objects needs to be further explored and grounded in empirical data. Using two case studies, we examine how learning designs in higher education courses support students' learning through work on shared knowledge objects, as well as how students experience these designs and the learning process. By means of complementary datasets, the learning design, enacted teaching practices, collaboration processes, experiences, and competencies learned are mapped and analysed. The findings are helpful in elucidating the learning taking place through interaction and practices mediated by shared knowledge objects, as well as informing the development of principles of a pedagogy of object-oriented collaborative learning, which provide practical recommendations and invite further research endeavors.
\end{abstract}

\section{Introduction}

In higher education, learning is undergoing a process of transformation at a similar pace as societal changes and technological advancements. The learning process is increasingly characterised as developing capacities to connect to remote knowledge resources, communities and (work) sites to engage with constantly renewing knowledge pools and address conflicting perspectives. Moreover, it has become increasingly common that students are expected to not only process and assess knowledge but also generate or co-produce knowledge solutions to complex problems (Halverson \& Sheridan, 2014; Shaw, Holbrooke, \& Burke, 2011), which often take the shape of knowledge objects (e.g., reports, guidelines, and software). Such skills and competences can be highly specialised and domain-specific as different disciplinary fields have distinct ways of producing and sharing knowledge (Jones, 2009). Concurrently, there are general aspects related to developing capacities for advanced knowledge work (i.e., capacities for understanding and creating knowledge, managing work and collaboration, or self-regulating one's performance).

Empirical knowledge is currently emerging about how students engage in meaningful interactions with peers, knowledge resources, and objects, as well as the social and digital-material environment in which such activities take place. Such findings contribute to a better understanding of learning viewed and enacted as a process of knowledge creation, which takes place through interactive practices that contribute to ideas being materialised into shared knowledge objects (Paavola et al., 2011). This type of learning entails activities that lead to students making meaning of knowledge and generating ideas they concretise through sustained discussion and collaboration with peers. Research studies have examined students' processes and shown, to some extent, how knowledge objects are evolving entities, shaped by the interactions between participants (e.g., Damşa, 2014a; Muukkonen \& Lakkala, 2009) and how students learn from engaging in knowledge practices that involve work forms with different types of knowledge 
Author copy

Crina Damsa \& Hanni Muukkonen (2020) Conceptualising pedagogical designs for learning through object-oriented collaboration in higher education, Research Papers in

Education, 35:1, 82-104, DOI: 10.1080/02671522.2019.1677751

objects (e.g., Damşa \& Ludvigsen, 2016; Kosonen, Muukkonen, Lakkala, \& Paavola, 2012; Laakkonen \& Muukkonen, 2019; Sansone et al., 2019). These findings also indicate a necessity to design support for the processes of learning through work on knowledge objects, which goes beyond the procedural or conversational aspects of collaborative learning. However, the current research is not making progress on advancing the conceptualisations of pedagogies that underline the learning process as one guided by work with shared knowledge objects.

In this study, we pursue an empirical examination of student groups working on different types of shared knowledge objects, with the ultimate aim to unveil the mechanisms of collaboration and knowledge work that cater learning as depicted above. The study conceptualises knowledge creation and objectoriented knowledge creation and object-oriented collaboration, and its use of established pedagogical models, such as inquiry- and project-based learning, following the assumption that proven pedagogies can support our quest for understanding how students learn through working on shared knowledge objects. In particular, we highlight aspects related to knowledge resources and object mediation because existing evidence is already provided by prior studies regarding the challenging and positive aspects of social interaction during collaboration, including engagement, motivation, peer support, and shared regulation (Järvelä, Järvenoja, Malmberg, Isohätälä, \& Sobocinski, 2016; Rogat \& Linnenbrink-Garcia, 2011; Volet, Summer, \& Thurman, 2009). The expectation is that the students' learning process and experiences are enriched by activities that emphasise active engagement and collaboration, including developing and working with shared objects. We pursue the study's aims by reviewing empirical research on collaborative inquiry and project work, examining two empirical cases that display students working in project groups to develop shared knowledge objects, and outlining the design choices of pedagogical relevance, all of which are discussed in the final section of the article.

\section{Empirical perspectives of pedagogical models emphasising knowledge creation}

Various pedagogical models (e.g., inquiry-based learning, problem-based learning, and project-based learning) are employed to support, in various ways, students' learning through work on ill-structured, openended problems, solved in collaboration and in the context of self-directed activities. Solving these problems collaboratively typically occurs through questioning, searching for information, researching and testing alternatives, discussing solutions with peers, and adjusting and revising results, actions specific to learning through inquiry and discovery. Although the activities may involve knowledge objects, the objects typically are not the analytical focus. These studies, however, offer a useful insight into the activities of relevance when attempting to design learning where work with knowledge objects is central. We review and synthesise studies that implement some of these models and attempt to highlight and use features of object-oriented collaboration.

Inquiry-based learning

Inquiry-based learning (IBL) is considered a form of active learning in which open-ended, student-directed inquiry or research drives the learning experience; it is branded as an 'umbrella' term, covering a range of pedagogical approaches that emphasise investigative work (Aditomo, Goodyear, Bliuc, \& Ellis 2013; Savery, 2006). The various forms of activity involved differ in the type of structure provided to the learner (i.e., from open-ended problems to clearly specified end-products) and the nature of the process (i.e., focused on defining and solving a complex problem, producing a material solution, or conducting analyses; Levy, 2008). The inquiry process is characterised by a question-driven mindset (Spronken-Smith \& Walker, 
Author copy

Crina Damsa \& Hanni Muukkonen (2020) Conceptualising pedagogical designs for learning through object-oriented collaboration in higher education, Research Papers in

Education, 35:1, 82-104, DOI: 10.1080/02671522.2019.1677751

2010), which often involves the participants sharing, understanding, and building new knowledge collaboratively.

Studies by Levy $(2008,2009)$ demonstrated the relationship between who frames the inquiry process (i.e., the teacher or the students) and how students perceive the inquiry experience based on a double frame of information gathering versus discovery. This latter categorisation identifies four modes of inquiry: identifying, pursuing, authoring, and producing. Levy's studies showed that students can engage in these activities by either working with an existing body of knowledge (e.g., problem-based learning in medical education) or constructing new knowledge. Concurrently, Spronken-Smith and Walker (2010) examined the potential of inquiry-based learning in strengthening the teacher-research nexus and identified three important qualifiers of the nature of IBL that depend on the degree of scaffolding provided: structured, guided, and open inquiry. In each of these types, students engage in an inquiry process with varying degrees of guidance and structure provided by the teacher or pedagogical design.

Students' perception of inquiry-based learning was examined by Levy and Petrulis (2011) and Spronken-Smith and Walker (2010). Their results indicate students misunderstand the principles of IBL by showing that students in the humanities and social sciences experienced this form of learning as interacting actively with a knowledge base and described the activity as knowledge gathering. Open inquiry appeared to be useful at the beginning and end of the study program; students are first 'encultured' in the domain knowledge and, by the end, pursue specific themes in-depth. In latter settings, there was more student-led activities and an increased capacity for research and collaborative practice. The latter study also examined students' reflection on the process of learning through inquiry and found that they had a limited understanding of this process.

A specific type of inquiry employed in higher education is progressive inquiry (Hakkarainen, 2003), which represents an instance of how inquiry-based learning is translated into small-group learning situations, and emphasises co-creating knowledge as part of the inquiry process. Inspired by the interrogative aspects of scientific inquiry and the knowledge-building approach, this type of collaborative inquiry sets as central, among others, the role of knowledge objects, how these objects are co-constructed and elaborated on (Paavola \& Hakkarainen, 2005), and how objects, in turn, can influence these processes. Empirical studies of progressive inquiry have examined in-depth inquiry processes associated with collaborative work in small project groups that constructed and elaborated shared knowledge objects (Damşa et al., 2010; Damşa, 2014a; Muukkonen, Lakkala, \& Hakkarainen 2005; Muukkonen \& Lakkala, 2009; Muukkonen, Lakkala, Kaistinen, \& Nyman, 2010; Sansone, Cesareni, \& Ligorio, 2016). These studies build on the assumption that learning is an activity that involves addressing complex knowledgebased problems, which requires collaborative inquiry and knowledge construction to reach appropriate solutions. The findings indicate that such complex processes require shared understanding, joint actions at the epistemological level, and a good balance between working with knowledge and managing the process. Moreover, differences were identified between student groups in the form and extent to which they were able to perform epistemological actions and monitor their inquiry discourse towards the exploration and development of a shared knowledge object.

Generally, the examined studies indicate that profiting from inquiry-based activities is not a straightforward issue. They all point to the need to better understand how students think of and organise their inquiry, as well as how they engage in and appropriate epistemological practices in inquiry-based activities, to provide them with the appropriate pedagogical design. 
Author copy

Crina Damsa \& Hanni Muukkonen (2020) Conceptualising pedagogical designs for learning through object-oriented collaboration in higher education, Research Papers in

Education, 35:1, 82-104, DOI: 10.1080/02671522.2019.1677751

\section{Project-based learning}

Traditionally, project-based learning has been viewed as a pedagogical model that involves students in completing projects that involve the real-world activities of experts (Kraijck \& Blumfeld, 2006). It is characterised by students pursuing knowledge with a clear, shared goal for the group, delineated by the project's objectives, and by asking questions they raise themselves. The questions guide students in investigating disciplinary issues under a teacher's guidance, which is expected to result in a product (e.g., a report, an experiment, or findings; Damsa \& Wittek, 2019; Spronken-Smith \& Walker, 2010). Participants pose such questions based on their own prior understanding and gain ownership of its knowledge-based explanation by delineating the scope of the self-defined problem. Thus, they learn to describe and pursue a knowledge issue comprehensively and be accountable for presenting the findings. Learners are usually provided with specifications for the desired end-product, and the guidance is oriented toward specific procedural aspects. Studies have shown that engaging with and managing the process are important elements of the activity and that students are faced with highly challenging situations when engaged in distributed projects (Muukkonen et al., 2010). They need to manage and generate their own activities in teams, which may be especially difficult when dealing with a customer is also involved (Dym et al., 2005; Stankovic, 2009).

In recent years the practice of carrying out customer projects has emerged, especially in business, engineering, and design studies (e.g., Denton \& McDonagh, 2005; Muukkonen et al., 2013; SeitamaaHakkarainen, Lahti, \& Hakkarainen, 2005). In relation to measuring learning gains, Bucciarelli (2003) criticised educational practices for reducing knowledge to static, distributable entities, where problemsolving usually takes place in a linear, unambiguous, and de-contextualised process. Prior findings have suggested that interdisciplinary or multi-professional learning is argued to amplify relational, mediated, transformative, and situated dimensions of learning and creativity (Latucca, 2002).

Project-based learning represents, as suggested above, a pedagogical model that illustrates work on knowledge objects (i.e., the product) in a way that can be rather structured and determined by disciplinary frameworks, with questions being raised about the space for in-depth inquiry and original contributions. These examples of pedagogical models employed in higher education contexts incorporate features of collaborative work with knowledge and knowledge objects in some form. The studies indicate the value of such models when attempting to set up the design of students' learning and developing capacities to work independently with knowledge. However, they also exemplify the complexity of such an endeavor and the need for clarifying how these processes take place and can be supported through pedagogical design and guidance.

\section{Conceptual framework of object-oriented collaboration and its design}

\section{Learning with knowledge objects}

In this study, sociocultural ideas regarding the mediated nature of learning (i.e., by intellectual means and tools; Säljö, 2010) and of learning through knowledge creation (Paavola et al., 2011) are relevant. Knowledge resources students engage with are mediational, which means they accumulate collective knowledge and experience and have instrumental value. Knowledge objects, inter alia, are developing entities and can be addressed in collaborative settings by negotiating, drafting, developing, and materialising new ideas and solutions (Miettinen \& Paavola, 2016). Knowledge objects are depicted as being the same as research objects or epistemological things, which are 'material entities or processes [...] that constitute the objects of inquiry' (Rheinberger, 1997, p. 28). An inner contradiction in relation to the 
Author copy

Crina Damsa \& Hanni Muukkonen (2020) Conceptualising pedagogical designs for learning through object-oriented collaboration in higher education, Research Papers in

Education, 35:1, 82-104, DOI: 10.1080/02671522.2019.1677751

nature of the object is highlighted, namely, that it is considered to have both a material and an ideational nature; thus, it can be both the realisation of material reality and, respectively, the object of thought. Rheinberger (1997) distinguishes objects as instruments (i.e., clearly defined and finished objects with an instrumental role) from epistemological or knowledge objects, which are question-generating, open to transformation and exploration, and have the potential to open new lines of inquiry. Knowledge objects are viewed as developing entities, addressed in collaborative settings by negotiating, drafting, developing, and materialising new ideas and solutions (Miettinen \& Virkkunen, 2005; Miettinen \& Paavola, 2016). Through iterative processes, knowledge is exchanged, adjusted and elaborated on, which allows for the emergence of new ideas and knowledge. However, working with knowledge is not necessarily something inherent to human activity, so developing ways of supporting it is needed. For the purpose of this study, the dual potential of knowledge objects is important. The complexity of this construct lies in its dynamic position in relation to knowledge creation processes, which can assign the object the role of a mediating tool or object of inquiry.

\section{Designing learning with shared knowledge objects}

We follow notions that depict learning design as a process of preparing situations and 'things' for others to learn, wherein the learners are active and engaged in generating knowledge and experiences, as well as developing competencies by solving problems, exploring, and seeking explanations. What is needed is a dynamic, process-bound design and an adjustment of the students' and teacher's activities in relation to the evolving learning processes, reflected in the term design for learning. It addresses various components, namely generic, physical, epistemological, or social-relational (Goodyear \& Dimitriadis, 2013). Further, it proposes that when conceptualising learning as a process wherein the learner has a central role in the types and content of learning being enacted, there is neither a causal relationship nor a way to determine learning experience and outcomes by, or directly from, the design. The learners are part of enacting the design, which makes both the design itself and learning situated components of a transformative process. The concrete elements, through which this is accomplished, can be tasks (i.e., making suggestions to the learner or using texts or other forms of communication) of the physical (i.e., artefacts or resources) and social architecture (i.e., participation, interactions, or types of activities). All these are to be interpreted, as well as pursued or used, by the learner in a way that highlights the importance of humans' transformative agency (Damşa, 2014b; Engeström \& Sannino, 2010) and interpretative powers. The design should generate environments for interaction and learning that are 'contingent and locally inhabited' (Jones \& DirckickHolmfeld, 2009), depending on how the learners are interacting with the knowledge objects.

The central aspect of our study is epistemological design (Carvalho \& Goodyear, 2016; Markauskaite \& Goodyear, 2017) and how it is represented by sets of tasks that facilitate students' work with shared knowledge objects. These are proposed activities, which not only guide and structure the knowledge work but also allow for emergent activities and gradual building the accumulated knowledge into the knowledge object. The knowledge objects are represented by an amalgam of material and conceptual (ideatic) resources, which can activate opportunities, as well as trigger and guide further development, when they are worked on through the planned learning activities. However, engaging with such complex objects can be challenging. We propose that meaningful learning is served when designs that include stepwise and gradual development for both mastering the subject matter and the experience to work with knowledge objects are provided. 
Author copy

Crina Damsa \& Hanni Muukkonen (2020) Conceptualising pedagogical designs for learning through object-oriented collaboration in higher education, Research Papers in

Education, 35:1, 82-104, DOI: 10.1080/02671522.2019.1677751

\section{Aims of the study}

Following the conceptual ideas outlined above and insights developed from examining the pedagogical models and studies showing both their benefits and limitations, we formulated three research questions that guided the empirical investigation:

1. What were the main characteristics of designing learning with knowledge objects as they emerge based on the two analysed cases?

2. How were learning activities with knowledge objects enacted in two higher education courses?

3. What were the students' perceived experiences and challenges?

\section{Methods}

We based this investigation on material from two distinct empirical cases (see Yin, 2013) focusing on two higher education courses in Norway and Finland, which we followed up intensively. The first case examined learning and teaching design in an undergraduate software engineering course offered by a university of applied science, with the main learning activity being a collaborative programming project. The second case investigated a master's degree course in educational psychology, which was arranged as a collaborative, progressive inquiry process. The case studies employed complementary approaches to collect data. Details of the contexts, participants, data collection, and analysis are presented separately for each of the two cases in the following paragraphs. In both cases, the dataset consists of a combination of data types, which reflects the richness of the learning design and an attempt to capture the process of working on knowledge objects from various angles (Table 1).

Table 1. Participants and dataset

\begin{tabular}{|c|c|c|}
\hline & Case 1: A software engineering course & Case 2: An educational psychology course \\
\hline $\begin{array}{l}\mathrm{N} \text { of students total } \\
(\mathrm{N} \text { groups }) / \text { data } \\
\text { analysed }\end{array}$ & $\begin{array}{l}5 \text { groups of } 3 \text { students }(\mathrm{N}=15) ; 2 \\
\text { females and } 13 \text { males; age } \mathrm{M}=21.8 \text {, } \\
\mathrm{SD}=6.8 \text {; second semester students } \\
\text { who had limited experience with } \\
\text { project work. }\end{array}$ & $\begin{array}{l}25+35(8+7 \text { groups) } / \text { responses from } \\
24 \text { (response rate } 40 \%) \text { students; } 19 \\
\text { females and } 4 \text { males; age } \mathrm{M}=31.0, \mathrm{SD}= \\
7.7 ; \text { first semester master's students who } \\
\text { had varied experience with project work. }\end{array}$ \\
\hline $\mathrm{N}$ of teachers & $\begin{array}{l}2 \text {, male; both had a background in } \\
\text { computer science; one with limited } \\
\text { teaching experience; both new to the } \\
\text { course. } \\
3 \text { teacher assistants, students from } \\
\text { older cohorts; knowledge of and } \\
\text { experience with programming in Java. }\end{array}$ & $\begin{array}{l}1 \text { in both iterations; the first iteration was } \\
\text { a new design of the course; experienced } \\
\text { teacher who had guided inquiry learning } \\
\text { processes previously. }\end{array}$ \\
\hline $\begin{array}{l}\text { Main assignment } \\
\text { features }\end{array}$ & $\begin{array}{l}\text { Collaborative project, the development } \\
\text { of a board game, programming } \\
\text { languages (Java), process } \\
\text { documentation. }\end{array}$ & $\begin{array}{l}\text { Literature-based investigation of a } \\
\text { learning-related research question in } \\
\text { educational psychology; co-authoring an } \\
\text { inquiry paper and presenting it to peers. }\end{array}$ \\
\hline
\end{tabular}


Author copy

Crina Damsa \& Hanni Muukkonen (2020) Conceptualising pedagogical designs for learning through object-oriented collaboration in higher education, Research Papers in

Education, 35:1, 82-104, DOI: 10.1080/02671522.2019.1677751

\begin{tabular}{|c|c|c|}
\hline $\begin{array}{l}\text { Main aspects in the } \\
\text { design of the } \\
\text { students' work with } \\
\text { knowledge objects }\end{array}$ & $\begin{array}{l}\text { Structure and content of collaborative } \\
\text { project: tasks; type of guidance; } \\
\text { content of the lectures; } \\
\text { communication with the teacher. }\end{array}$ & $\begin{array}{l}\text { Begin with initial, fuzzy questions based } \\
\text { on the students' own prior knowledge; } \\
\text { collaboration to answer inquiry questions, } \\
\text { lectures, articles, and other resources; } \\
\text { learn about scientific co-authoring, expert } \\
\text { practices of solving ill-defined problems } \\
\text { in groups. }\end{array}$ \\
\hline Types of data & $\begin{array}{l}\text { - Observations of lectures, coaching } \\
\text { hours, labs, and course documents; } \\
\text { - Video-recorded group discussions; } \\
\text { - Products of group work; } \\
\text { - Pre-and post-course interviews with } \\
\text { the teachers; } \\
\text { - Post-course interviews with TAs } \\
\text { and the student groups. }\end{array}$ & $\begin{array}{l}\text { Learning environment, slides; } \\
\text { - Group essays and self-evaluations; } \\
\text { questions on the CKP questionnaire } \\
\text { (Muukkonen et al., 2017) regarding the } \\
\text { positive and challenging aspects of the } \\
\text { course. }\end{array}$ \\
\hline Types of analyses & $\begin{array}{l}\text { Content analysis of observations; } \\
\text { thematic analysis of interviews and } \\
\text { group discussions. }\end{array}$ & $\begin{array}{l}\text { Content analysis of the evolution of the } \\
\text { inquiry questions; thematic analysis of } \\
\text { group self-evaluations and open-ended } \\
\text { responses. }\end{array}$ \\
\hline
\end{tabular}

\section{Case 1}

\section{Context and participants}

As part of a larger research project examining knowledge practices and student learning in higher education ${ }^{1}$, this study was conducted in a computer engineering bachelor's degree program at a university of applied sciences. This program offers bachelor's degrees in the engineering and information technology fields and was selected because of its specific domain delimitation and the measures taken to introduce a research-based curriculum. Direct access to the sample group was obtained through a call to the students and teachers, with the participating students signing up voluntarily. The fifteen participating ( 2 female, 13 male) students were organised into four project groups.

\section{Learning activities during the course}

We observed and documented an introductory course in program development, a bachelor's level second semester course introducing students to advanced object-oriented programming knowledge and projectbased programming using Java as a programming language. The course (10 ECTS) was planned, designed, and taught by a lead teacher, supported by another lecturer and the teaching assistants, or lab leaders (TAs). Both the teachers held a $\mathrm{PhD}$ in computer sciences and conducted lectures on themes within their field of expertise.

The course contained varied learning and instructional strategies (see Figure 1.). Bi-weekly lectures were provided during a seven-week period to introduce the programming languages of web design and development (i.e., Java and CSS). In the weekly tutorial and bi-weekly lab sessions, the students had the opportunity to work on the two mandatory individual assignments and receive feedback on the project from TAs. The collaborative project consisted of the students developing a digital board game, called 'Game of

\footnotetext{
${ }^{1}$ QNHE - Quality in the Norwegian Higher Education: Pathways, Practices and Performances
} 
Author copy

Crina Damsa \& Hanni Muukkonen (2020) Conceptualising pedagogical designs for learning through object-oriented collaboration in higher education, Research Papers in

Education, 35:1, 82-104, DOI: 10.1080/02671522.2019.1677751

life' or GoL, using the principles, programming languages, and strategies learned during the course and students individually documenting their programming work. Each individual student was required to have fulfilled the mandatory individual assignments prior to engaging in the group work. The groups met twice per week during the assigned lab time, but they were free to also meet or work outside these hours. The lab leaders were present during the lab hours and answered the groups' or individual students' questions; questions regarding the development process could be addressed at any point through email messages sent to the teachers and TAs. The software product was first assessed, in a formative fashion, two weeks prior to the final deadline, with feedback being provided by the teaching staff. The project outcome (i.e., software and documentation) was the main material used for assessment in this course. The groups used online platforms and tools, tailoring their use in accordance with their needs. Github, an online repository and collaborative platform used by programmers, was used by the teacher to make course materials, assignments, guidelines, and links to resources available, as well as by the students as workspace. All four groups used Facebook group pages for communication.

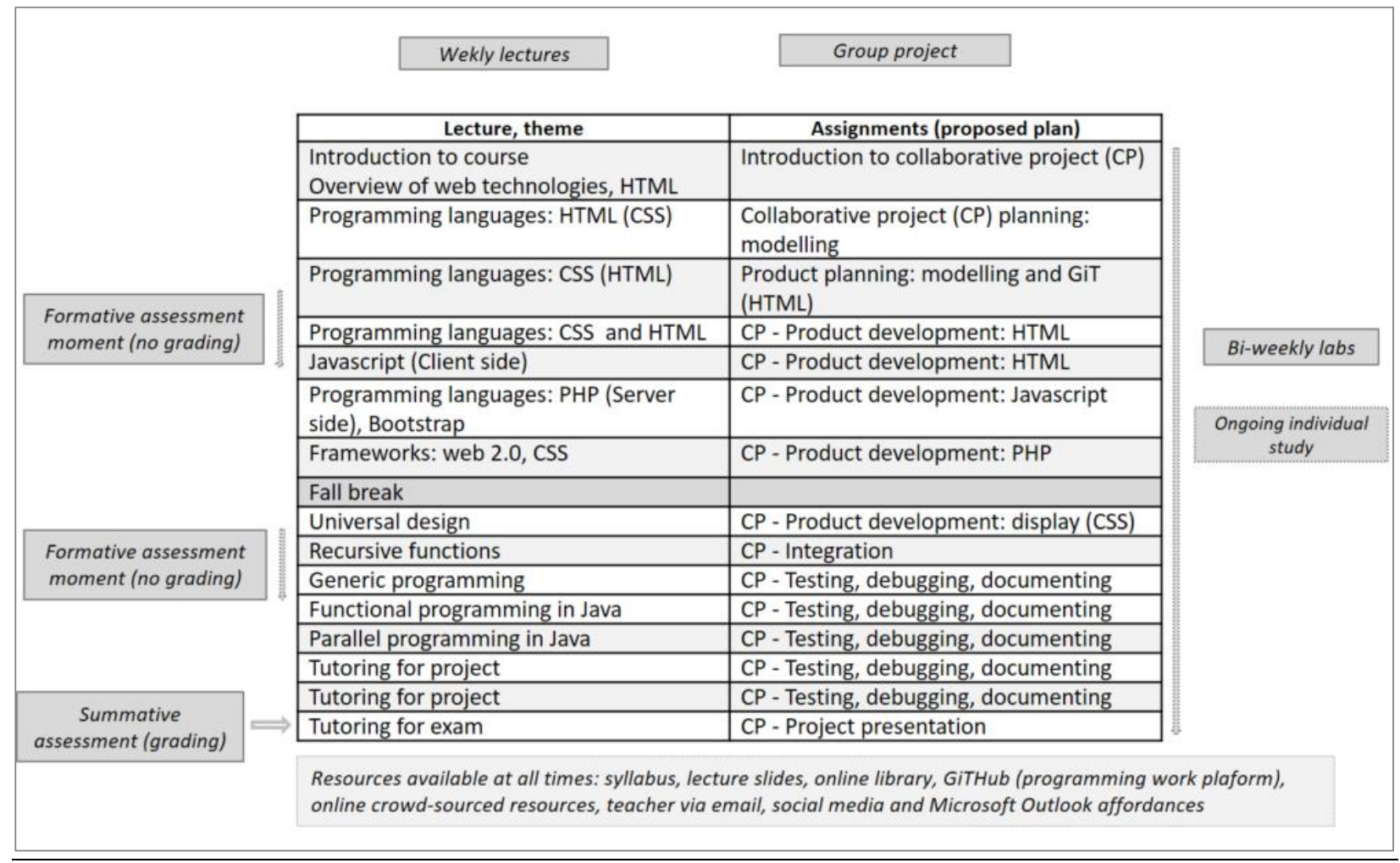

Figure 1. Weekly activities in Case 1

\section{Data collection}

We collected self-reported data (via interviews with each group), interaction data (via online communication and video recordings of group meetings), knowledge objects (i.e., notes, mock-ups, and versions of the products), and course materials.

\section{Case 2}


Author copy

Crina Damsa \& Hanni Muukkonen (2020) Conceptualising pedagogical designs for learning through object-oriented collaboration in higher education, Research Papers in

Education, 35:1, 82-104, DOI: 10.1080/02671522.2019.1677751

\section{Context and participants}

Case 2, the 5 ECTS psychology of learning course, is the initial course in the educational psychology and educational sciences master's degree programs at a research university in Finland. Some of the participants had just returned to studies after working for a period of time. The teacher invited the students to participate in the course by answering questionnaires and giving consent to use the course materials for research purposes. Materials for which consent was not given were excluded from the data. The design of the course was focused on guiding the students through an open-ended question-explanation process in groups of 3-5 students. The learning objectives were related to theoretical knowledge, understanding learning at different ages, being able to apply this knowledge to support growth and development, and defining and solving complicated knowledge problems to practice working with knowledge like an expert.

\section{The course's learning activities}

The eight-week course consisted of weekly lectures, individual study, face-to-face collaboration, and online co-authoring (see Figure 2). First, each student was asked to formulate questions about something they would like to understand more fully in educational psychology. Then questions were shared and discussed in groups of 2-3 students with the aim of selecting and presenting two important questions to the entire class. These were written using the Padlet tool, so the questions were visible to the entire class. Then, the students were asked to identify larger themes and clusters of questions, which were, again, discussed in groups. Next, the students were instructed to arrange themselves into groups of 3-4 and write down an initial, large inquiry question for their group. To provide a meta-level model for the inquiry, the model of progressive inquiry (Muukkonen et al., 2005) was introduced. These groups were instructed to engage in discussing and documenting the objectives of their work, advance their knowledge with relevant concepts and evidence through a literature search, write a paper on Google Docs (shared with the entire class), and give a presentation, as well as feedback, to another group. The teacher provided formative feedback during class (e.g., providing guidance on materials and academic writing, as well as focusing the inquiry) and evaluated the final group project. 
Author copy

Crina Damsa \& Hanni Muukkonen (2020) Conceptualising pedagogical designs for learning through object-oriented collaboration in higher education, Research Papers in

Education, 35:1, 82-104, DOI: 10.1080/02671522.2019.1677751

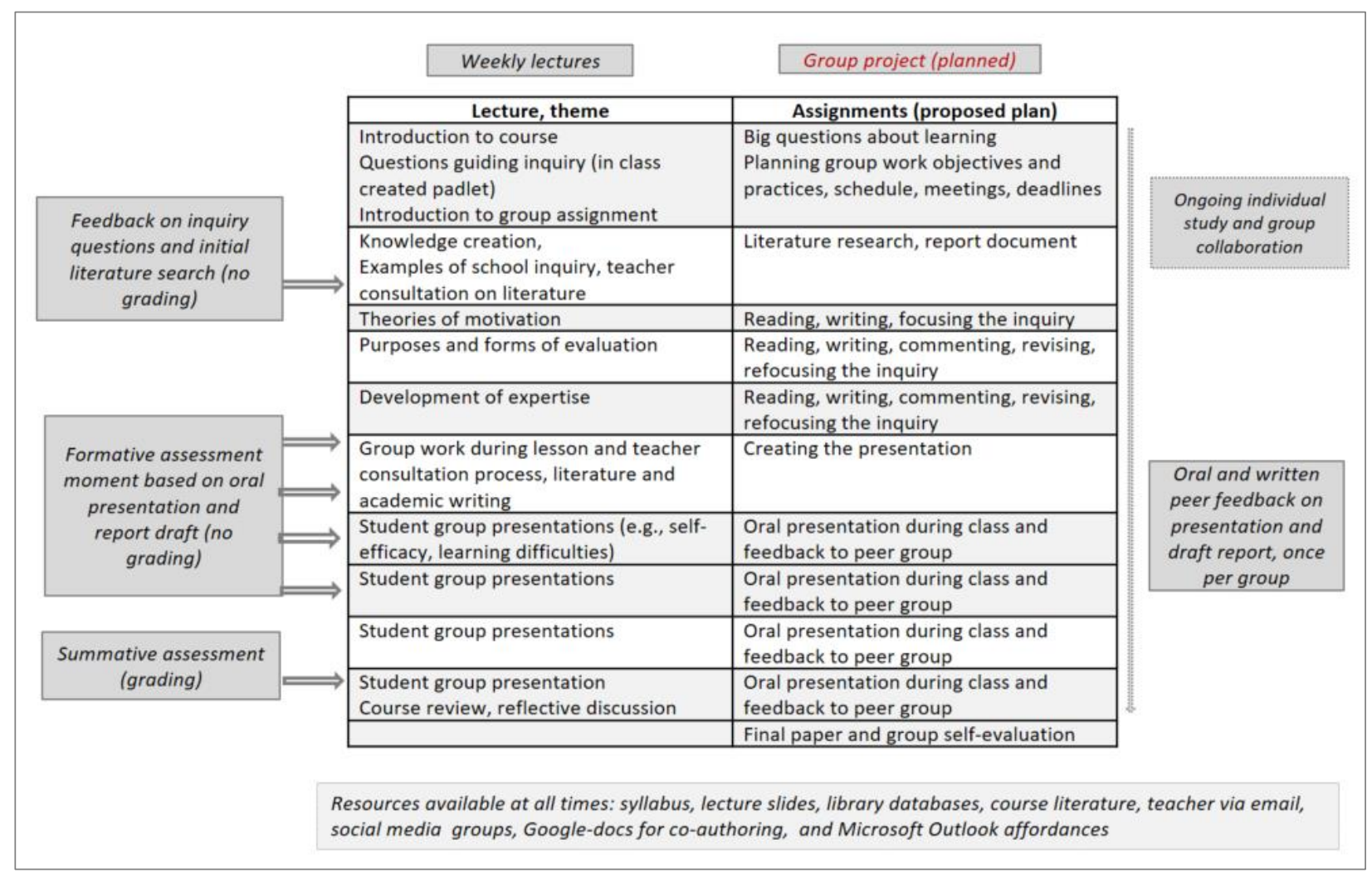

Figure 2. Weekly activities in Case 2

\section{Data collection}

This study included collecting the students' answers to three open-ended questions from the Collaborative Knowledge Practices (CKP) questionnaire (Muukkonen et al., 2017) regarding what was positive and what was challenging about the course, as well as any additional comments. The students' group presentations, essays, and self-evaluations (i.e., discourse on content, group responsibility and reaching goals, interaction, and co-authoring the essay) were collected, as well as peer comments from the virtual learning environment.

\section{Data analysis of Cases 1 and 2}

We employed a combined technique building on a thematic analysis of the interaction and self-reported data (Braun \& Clarke, 2016) and a qualitative content analysis of the course documents and objects involved and the open-ended responses and group self-evaluations (Bazeley, 2013). In the analyses, we allowed relevant aspects to emerge from the data, which is an inductive approach. A thematic analysis emphasises the students' experiences and the positive solutions discussed and written by the students regarding collaboration during their course. A combination of the data from the two cases (Case 1: 4 groups/16 students and Case 2: 14 student groups and 24 individual responses), with a departure point in the selfreported data, was used to examine the students' experiences, challenges, and positive solutions related to their work with knowledge objects, resulting in the identification of three central themes:

1. how interaction took place,

2. how knowledge resources were utilised, and

3. how the developing object mediated the collaborative work. 
Author copy

Crina Damsa \& Hanni Muukkonen (2020) Conceptualising pedagogical designs for learning through object-oriented collaboration in higher education, Research Papers in

Education, 35:1, 82-104, DOI: 10.1080/02671522.2019.1677751

Furthermore, these themes could be analysed based on the more concrete phase or aspect of inquiry it was addressing. Based on the data, these were set as the initiation of inquiry or project work, combining interests, co-authoring, depth of inquiry, academic writing, group responsibility, use of ICT, the schedule, and finalising the work.

\section{Findings}

\section{Designs for learning with knowledge objects}

In the software engineering case, the lead teacher considered the relevant domain-specific sequence of curriculum elements, how these should be introduced through various course activities and teaching methods, and feedback and assessment activities. The teachers' and students' reports indicate that the epistemological aspects of the envisioned course design clearly reflected a pedagogical vision regarding project-based learning, wherein concrete knowledge objects were being developed and the specific software engineering domain knowledge and skills to be learned. The enacted design differed, to some extent, from the envisioned design. While some activities were pursued and enacted as planned (i.e., lectures and lab sessions), others proved to be more challenging to realise (e.g., group work). Adjustments were made during the course to create a more tailored approach to match the students' individual needs, and in the project groups, to the types of advisory work.

The design broadly reflected the teachers' conceptions described in the interviews, wherein the lead teacher indicated a clear agenda for redesigning the course in terms of aims, types of organised course activities, course content, and student support and guidance in the work with knowledge objects. Another aspect to be addressed through the re-design was the practical training (exercises), which is crucial for developing basic programming skills ('...new tools or programming environments are being introduced, and we need to ensure the students engage with these to work on their project and product...', Midterm interview with T1). Through this practical component, the students were exposed extensively to collaborative work with knowledge objects, which is a practice they need to engage with in preparation for their future profession.

In Case 2, formulating the inquiry question was the first task of the course and was used by the teacher to encourage an explanation seeking process so that students would actively connect their prior knowledge to major research topics in educational psychology. Course literature was provided, but assistance was given to the students during their search for journal articles, handbooks, chapters, and peer-reviewed materials on the topics of choice. The expectation was that both Finnish and English language research literature would be read and referenced. However, the first discussions revealed that there were apparent differences between students in their fluency in linking everyday phenomena to the central concepts in educational psychology. The students were guided to begin a literature search immediately, wherein they searched for articles (several journals, databases, library resources, specific books, and materials stored in the course's online environment, Optima) and documented, in each group's shared document, literature that they found during the first week and briefly describe how it contributed to addressing the inquiry question. Examining the other groups' materials was also encouraged. After the first week, the teacher read through all the descriptions the students had found so far and, in class, sat down with each group to evaluate and plan together. The teacher explained that in addition to learning the content knowledge, the purpose of working with a very open problem-space was three-fold: 1) to engage in steps that resembled a master's thesis' initial framing process, practice them in groups before carrying them out individually the following 
Author copy

Crina Damsa \& Hanni Muukkonen (2020) Conceptualising pedagogical designs for learning through object-oriented collaboration in higher education, Research Papers in

Education, 35:1, 82-104, DOI: 10.1080/02671522.2019.1677751

year; 2) practice academic writing with scientific expressions and referencing; and 3) practice the expertlike process of tackling complicated questions in collaboration and engage in reviewing, commenting on, and improving the group essay iteratively. Table 3 provides a summary of the envisioned design and how aspects of this design were enacted in the course.

\section{Enacting learning designs with knowledge objects}

How the designs envisioned by the teacher were enacted was influenced by the students' understanding of them and the students' participation (or lack thereof) in the planned activities. In the software engineering course, the student groups organised their collaborative programming, aimed at developing the knowledge object, by employing structured sets of steps. The programming work consisted of individual coding and frequent discussions of coding strategies, emerging problems, and an iterative trial-and-error strategy. The latter involved mutual progress updates, the identification and improvement of errors, the integration of individual contributions when correct and re-assessment when invalid, followed by a new iteration and the production of a new version of the knowledge object. The group discussions frequently raised new issues and questions, which contributed to advancing both the inquiry and the knowledge object. Generally, the discussions were object-bound, employing technical language and content, without much elaboration of knowledge but attempting to 'fit' the process and product in a pragmatic way, as shown in Excerpt 1 :

1. Interviewer: How did your collaboration work out?

2. Eddy We sat together and discussed a lot... ideas, problems, solutions, the parts that we developed, what needed to be done.

3. Seb: $\quad$ Each of us gave some input, but generally, we analyzed issues together, and looked for solutions together, and asked for feedback and then discussed it... When it was clear, each of us had some task to work on.

4. Matt: And then we returned to the group again, to check how it worked out with programming that... (Interview, Group 3

Problems raised by individuals were usually addressed by the entire group as the interview protocol in Excerpt 1 reveals. This was done through conversation and by considering alternatives, identifying and pointing out (though physical gestures) possible errors, and drawing upon resources, for example, by asking feedback from the TAs. The use of online knowledge resources provided by the teacher or the TAs (e.g., w3schools and the online validation tool) or found by the students within the expert programming community, was one aspect revealed by the analyses. Strategies learned during the students' inquiry and the resources mobilised are identified as instrumental in generating solutions. The collaborative discourse and problem-solving actions were usually closely bound to the knowledge objects.

In the educational psychology course, students worked in groups based on their interests formed around the thematic inquiry questions. They first created a shared document for their group and, individually, conducted a search for relevant articles, books, and other resources to answer their inquiry question, in addition to teacher-provided course materials. Some students quickly found relevant literature, while others had difficulty identifying the key terms or found reports rather than peer-reviewed materials in their search. The second and third week included a check with the teacher regarding their progress and a discussion of how to focus the inquiry. The students engaged in co-authoring an essay based on the outcomes of their literature search to answer a research question. Questions evolved significantly through the identification of relevant concepts and research lines and by redefining the question, and hence, the essay became more focused and excluding some topics. For instance, one group began with the question, 
Author copy

Crina Damsa \& Hanni Muukkonen (2020) Conceptualising pedagogical designs for learning through object-oriented collaboration in higher education, Research Papers in

Education, 35:1, 82-104, DOI: 10.1080/02671522.2019.1677751

'How to learn even if the topic is not interesting?', and finally presented an essay on the 'Relevance of selfregulation and academic emotions as part of higher education students' motivation'. The students' face-toface discourse and online collaboration were tied to co-authoring their presentation and the essay, as well as integrating the feedback received from a peer group.

Table 3. Thematic analysis of challenging aspects of the design of interaction, knowledge resources, and objects mediation during inquiry (examples from Cases 1 and 2).

\begin{tabular}{|c|c|c|c|}
\hline $\begin{array}{l}\text { Aspect of } \\
\text { inquiry }\end{array}$ & $\begin{array}{l}\text { Design of interaction as } \\
\text { part of inquiry process }\end{array}$ & Knowledge resources & Object mediation \\
\hline Initiation & Starting too slowly. & $\begin{array}{l}\text { Exploring openly available sites } \\
\text { containing resources. } \\
\text { Defining the inquiry space and } \\
\text { then conducting a focused } \\
\text { examination of the research } \\
\text { literature. }\end{array}$ & $\begin{array}{l}\text { Trial-and-error in depicting } \\
\text { object features. } \\
\text { Broad topics in multiple } \\
\text { directions. }\end{array}$ \\
\hline $\begin{array}{l}\text { Combining } \\
\text { interests }\end{array}$ & $\begin{array}{l}\text { Sharing prior knowledge } \\
\text { and experience with } \\
\text { programming. } \\
\text { 'Dare' to talk about own } \\
\text { interests and compromise. }\end{array}$ & $\begin{array}{l}\text { How to coordinate the students' } \\
\text { shared effort while searching } \\
\text { for resources. } \\
\text { How can we choose a topic that } \\
\text { everyone has an interest in and } \\
\text { something to contribute? }\end{array}$ & $\begin{array}{l}\text { Reaching a consensus on most } \\
\text { salient features of the shared } \\
\text { object. } \\
\text { Finding the 'big picture'; each } \\
\text { student was acting } \\
\text { independently without } \\
\text { understanding how the ideas } \\
\text { were linked. }\end{array}$ \\
\hline Co-authoring & $\begin{array}{l}\text { Identification of design } \\
\text { requirements. } \\
\text { Defining the shared } \\
\text { learning goals in the } \\
\text { beginning; different } \\
\text { writing and working } \\
\text { habits. }\end{array}$ & $\begin{array}{l}\text { Agency in the search; selecting } \\
\text { and using the knowledge } \\
\text { resources. }\end{array}$ & $\begin{array}{l}\text { Uneven contribution to the } \\
\text { product development; } \\
\text { challenges encountered with } \\
\text { integration. } \\
\text { Plan the overview; not } \\
\text { commenting early enough on } \\
\text { each other's text; how to make } \\
\text { the entity coherent when parts } \\
\text { of it are unfinished. }\end{array}$ \\
\hline $\begin{array}{l}\text { Depth of } \\
\text { inquiry }\end{array}$ & $\begin{array}{l}\text { Integration of insights. } \\
\text { Discussions of how to } \\
\text { revise the essay were not } \\
\text { frequent enough. }\end{array}$ & $\begin{array}{l}\text { Lack of skill in critically } \\
\text { analysing the resources. } \\
\text { Not addressing the topic } \\
\text { critically; based on the students' } \\
\text { ideas; needed more depth. }\end{array}$ & $\begin{array}{l}\text { Unclear how to pursue aspects } \\
\text { that were not intuitive in } \\
\text { relation to the object. } \\
\text { Discussion not focused on the } \\
\text { essay content. }\end{array}$ \\
\hline $\begin{array}{l}\text { Academic } \\
\text { writing }\end{array}$ & $\begin{array}{l}\text { Need for more reciprocal } \\
\text { oral and written } \\
\text { comments in the group. }\end{array}$ & $\begin{array}{l}\text { Knowledge about academic } \\
\text { writing, referencing, and } \\
\text { locating scholarly sources. }\end{array}$ & $\begin{array}{l}\text { Uneven competencies. } \\
\text { 'Heavy and slow to produce } \\
\text { text'; writing the group essay } \\
\text { was very challenging but also } \\
\text { rewarding; not stepping on each } \\
\text { other's toes when editing text. }\end{array}$ \\
\hline
\end{tabular}


Author copy

Crina Damsa \& Hanni Muukkonen (2020) Conceptualising pedagogical designs for learning through object-oriented collaboration in higher education, Research Papers in

Education, 35:1, 82-104, DOI: 10.1080/02671522.2019.1677751

\begin{tabular}{|l|l|l|l|}
\hline $\begin{array}{l}\text { Group } \\
\text { responsibility }\end{array}$ & $\begin{array}{l}\text { Practices of } \\
\text { collaboration. } \\
\text { Taking responsibility as a } \\
\text { group and contributing } \\
\text { equally. }\end{array}$ & $\begin{array}{l}\text { Creating an overview of } \\
\text { available resources and } \\
\text { integration. } \\
\text { Level of effort varies depending } \\
\text { on the individual student's goals } \\
\text { and motivation. }\end{array}$ & $\begin{array}{l}\text { Coordination of understanding. } \\
\text { Obtain relevant input from each } \\
\text { member to achieve goals. }\end{array}$ \\
\hline Use of ICT & $\begin{array}{l}\text { Intensive use of ICT and } \\
\text { media. } \\
\text { Working mainly online; } \\
\text { little opportunity for face- } \\
\text { to-face communication. }\end{array}$ & $\begin{array}{l}\text { Working online limited the } \\
\text { students'/groups' discussion of } \\
\text { the content. }\end{array}$ & $\begin{array}{l}\text { Technology not working, } \\
\text { difficulties editing online. }\end{array}$ \\
\hline
\end{tabular}

Experiences and challenges when learning with knowledge objects

Based on the student's interviews and self-reflection, three categories of challenges were highlighted: designing interaction as part of the inquiry process, using knowledge resources, and the developing object mediated the collaborative work. The analysis revealed (see Table 3 ) that the interaction theme is common to most types of collaboration, and the challenges related to sharing knowledge and responsibility, scheduling, and establishing practices for collaboration were also identified by the students in these two cases. The challenges related to using and working with knowledge resources were related to finding and exploiting suitable resources, sharing critical analyses of the sources, understanding academic writing practices, and creating an overview and documentation of various resources. The thematic analysis of object mediation highlighted, in particular, challenges related to finding the big picture and reaching a consensus about the objectives of the shared work, coping with uneven contribution, and obtaining timely input from all team members, as well as students not putting enough effort into collaborative editing. In the Software Engineering case, the students reflected on concrete work with object as a mediator for making meaning of domain knowledge and skills.

'Bringing our ideas together, how to go about the principles, was difficult. But it helped us focus. Kind if gave guidance to what we were supposed to do because much of the work was floating. Shared object supporting converging intentions, ideas, actions'. (Interview Group 1)

In this case, the shared object the students worked on is viewed as a mediating element that connects the students with the knowledge domain and makes the abstract knowledge available in the course. However, the object is not only a materialisation of the students' knowledge; they also indicate that it supported the convergence of intentions, ideas, and actions at the group and individual level. They also indicate how various people in the course context were part of their process of learning through developing the object.

'And he (TA) just doesn't write the solutions, he tries to, like he gives more help and we try to solve it. Yeah, you learn a lot like that... you don't just get a finished code; no, you have to think a little bit about it'. (Interview Group 2)

The students acknowledge the way the expertise of the TA was provided as part of their work with the knowledge; it was used to facilitate their process rather than provide solutions. This type of relational 
Author copy

Crina Damsa \& Hanni Muukkonen (2020) Conceptualising pedagogical designs for learning through object-oriented collaboration in higher education, Research Papers in

Education, 35:1, 82-104, DOI: 10.1080/02671522.2019.1677751

resources is seen as important in that it can feed the process by providing needed input and be part of offering the guidance needed to sustain it.

Case 2 results highlighted in the student groups' self-reflection on how the various resources and need for revisions of their group essay were addressed. The groups also reported on how they proceeded to focus on the entity, create common objectives for their work, and aim for a well-integrated essay.

'We edited our work with the help of peer group comments. In the end, we checked our research question and [our] answer to it in the essay and the good fit between the introduction and the conclusions'. (Group Self-evaluation)

The students worked in groups to co-author a paper and reported on the co-authoring challenges they encountered: 'In some ways, it was challenging to work on a group essay. There are different styles to starting and working'; for example, 'someone could start writing already before we had come to a proper agreement about the topic'. It was considered very important to negotiate the themes of inquiry, which took several iterations: 'Matching the interest of different persons while making the group work, but this mainly was about selecting the theme boundaries'. This became particularly explicit when the group was not taking time to write about the materials they found or if some members had not made much progress in their work. Once the group members had written the first draft of their essay, they could collaboratively evaluate how the entity was forming and what steps they needed to take to fill the missing gaps or tie parts together.

Reserving time either after or during lectures to give groups the opportunity to ask for suggestions and guidance on framing the inquiry became an important aspect. For instance, one group studying how emotions affect learning found themselves confused after an attempt to write a definition of emotions. They had identified that in the English language, the term emotion is used for both the earlier automatic reactions and the later, more conscientious identification of emotions, while in the Finnish language literature, these are expressed with different terms. After a discussion on the value of this discovery and ways to write these definitions, they again felt comfortable continuing the process. Students appreciated that they could specify the objective and research questions, 'which influenced significantly [their] motivation towards the task'.

\section{Discussion}

The two cases represented different fields in higher education, namely, software engineering and educational psychology. The findings indicate that in both cases, tying the content of learning to competence development supports sustained engagement, helping generate coherent learning activities and gradual advancement, through sub-tasks, towards the final knowledge object. In the next paragraph, we discuss differences between the program contexts with respect to the three aspects expressed in the research questions that seem significant to the way the learning processes as they emerged based on the two analysed cases: 1) the way learning activities involving knowledge objects were enacted in the two courses, 2) the students' experiences and challenges, and 3) the main characteristics of designing learning with knowledge objects.

\section{Aspects important to object-oriented collaboration}

One essential aspect that played a role in how the inquiry process unfolded were the aims of the learning tasks. Following the model proposed by Spronken-Smith and Walker (2010), the software engineering students performed a task that required constructing knowledge and materialising it in a tangible knowledge 
Author copy

Crina Damsa \& Hanni Muukkonen (2020) Conceptualising pedagogical designs for learning through object-oriented collaboration in higher education, Research Papers in

Education, 35:1, 82-104, DOI: 10.1080/02671522.2019.1677751

object, a webpage. The first context brought about exploration processes that required knowledge gathering and establishing abstract linkages among new concepts, as well as between concepts and the reality of the case. It challenged students to distance themselves from their usual way of thinking about knowledge and teaching and adopt domain-specific standards of thinking and practice. Both appeared challenging for the students, with the most striking difficulties expressed in their lack of understanding of conceptual knowledge, which affected their ability to perform the task adequately. While it can be argued that the knowledge introduced was new and that it is, indeed, difficult to work with abstract knowledge without being able to anchor it in practice, the question emerges regarding what is to be expected from students when performing such tasks and what types of tasks and knowledge they should be exposed to in order to facilitate meaningful learning (see also Damşa, 2014a). The process and the way it unfolded took a different turn, characterised by a rather strict organisation and following standardised procedures. To some extent, these students appeared more aware of the nature of the object-oriented nature of their collaboration as the process unfolded. They verbalised strategies that helped outline the work, identified available resources, and maintained an investigative attitude throughout the process. They succeeded in fulfilling the task, with regard to inquiry elements, by re-constructing the domain knowledge at the application level. To return to Spronken-Smith and Walker's model and findings, the current study identified a higher awareness of students concerning the types of tasks they were to engage in, but interestingly enough, it did not lead to a more advanced and sophisticated inquiry process. This was most visible in the way the students worked with knowledge sources, where they succeeded in gathering resources but did not always take a critical approach to the knowledge and information these sources made available.

In the educational psychology course, the students had a very open problem-space and needed to self-organise their inquiry around group-selected inquiry questions. Structuring the process by means of deadlines for the literature research, a draft version for peer commenting, class presentations, and comments on their peer groups' work were provided. However, it was not enough for about a third of the groups to start on time and bring their individual inquiry contributions by authoring the actual texts, making an integrated entity of the essay topic, or co-editing the texts of their group members as suggested by the assignment instructions. Therefore, ways to overcome this problem by providing additional guidance, prompts, and worked examples on academic authoring and referencing practices are needed, as well as ways to engage students in the needed activities early in the inquiry.

With regard to the type of learning activities enacted and actual involvement in knowledge creation practices, a parallel can be drawn between the model and findings of studies conducted by Levy and colleagues $(2007,2008,2011)$. Their model provides an interpretation of types of inquiry, which adds some alternative details to the Spronken-Smith and Walker model. The software engineering students' task required and encouraged them to engage in 'authoring' (i.e., a teacher-framed task rather than an exploration of the students' own questions) and 'producing' (i.e., an inquiry framed by the teacher that resulted in the students constructing new knowledge). Our findings clearly show that the software engineering students engaged with the domain knowledge in a more interactive way; they drew it in, twisted it, and tried to modify and adjust it in the process of producing their code. The way the software engineering students' inquiry was framed allowed engagement in the creation of a shared knowledge object, an aspect emphasised in progressive inquiry studies (Muukkonen et al., 2005; Muukkonen \& Lakkala, 2009) and collaborative learning around shared knowledge objects (Damşa, 2014a). These studies indicate that the interaction, at both the epistemological and regulative level, was enhanced by the presence of this shared object. Our findings show similar trends. The software engineering groups' work began with developing an object, their 
Author copy

Crina Damsa \& Hanni Muukkonen (2020) Conceptualising pedagogical designs for learning through object-oriented collaboration in higher education, Research Papers in

Education, 35:1, 82-104, DOI: 10.1080/02671522.2019.1677751

shared codes, which became a trigger for new questions, problems, and inquiries; it became a truly epistemological object. The resources used by these groups were also incorporated into and had an impact on the inquiry by shaping the direction of the process as the students` knowledge of various coding procedures increased. In the educational psychology course, the integration of the students' own questions about challenges in everyday life with research-based evidence and definitions was the motivation for the inquiry and the knowledge creation challenge in a group format. Beginning with developing the inquiry question and then presenting the body of literature coherently in the group essay provided the shared object for the group. At the course level, the groups had a rather vaguely shared object: understanding and teaching each other about the inquiry topics in groups. Therefore, these aspects of defining more clear-cut courselevel shared objects could be the next aim of course development. Following these findings, the value of the knowledge objects and their epistemological role are obvious, although building this aspect into the inquiry tasks might represent a design challenge.

Furthermore, our findings point to the importance of scaffolding for new and more advanced students in the epistemological and procedural aspects of inquiry-based activities. The software engineering students found many support structures for programming work, which were aimed at advancing the knowledge object, naturally embedded in the knowledge resources of their domain within, but mostly outside of, the institutional context. The software engineering students were presented with a structured inquiry task in which the problem was clearly specified by the teacher, and the resources, constraints, and strategies involved in addressing the problem were also outlined, partly by the teacher and partly by the community standards. During the project period, the level of scaffolding was also very limited. This was experienced as frustrating for the students, but none of the groups truly stumbled since they could rely on community resources, which provided them with a sort of alternative support. In contrast to the teaching domain, the software development community is characterised by a considerable set of standards and procedures, as well as easily accessible artefacts that enable the pursuit of such standards and validation instruments (see Mackenzie, 2005). The students had access to these and could engage in object-oriented inquiry even when guidance or scaffolding was absent. The educational psychology students were offered a model of the inquiry (progressive inquiry model), resources available in the network, and teacher guidance, but similar professional resources or standards, apart from American Psychological Association (APA) guidelines for academic writing, were not offered. In a sense, the software engineering and educational psychology students were independent and self-reliant in their inquiry and organised their process in what could be characterised as a self-directed object-oriented inquiry.

\section{Towards pedagogies for object-oriented collaborative learning}

Among the primary aims of this study was examining shared knowledge objects as conducive to a process that provides opportunities for learning and for participants to address open-ended and complex problems. The characteristics of and the way the collaboration and activities take place are, in an integrated manner, connected to the knowledge objects that emerge from and which are developed through this interaction. Muukkonen et al. (2005) and Muukkonen and Lakkala (2009) analysed some aspects of object-oriented practices but did not perform an in-depth analysis of the developing knowledge objects. A number of activity theoretical studies (Miettinen, Lehenkari, \& Tuunainen, 2008) depicted the role of knowledge objects in various organisational processes and showed that (ready) objects can function as mediating elements in collective activities or learning. The current examination went beyond the merely mediatory role of knowledge objects and focused more on their development through interaction, along with the 
Author copy

Crina Damsa \& Hanni Muukkonen (2020) Conceptualising pedagogical designs for learning through object-oriented collaboration in higher education, Research Papers in

Education, 35:1, 82-104, DOI: 10.1080/02671522.2019.1677751

students' perception of how this process served their learning. It examined how the content and development of the shared knowledge objects played a role in the co-construction process. The study purports that complex and open-ended problems create the potential for the joint construction of knowledge and knowledge objects. In this context, knowledge objects are seen as concrete entities (Paavola \& Hakkarainen, 2005, 2009) in the sense that they materialise knowledge collected and constructed during the interactions of collaborating groups.

One distinctive contribution of this empirical examination is its attempt to follow and guide the development of knowledge objects worked on by the students. This analysis focused on the knowledge objects from the moment they entered the interaction process (e.g., ideas, concepts, and software) until they were materialised and elaborated on to form the final objects produced by the groups. The results of the present study show how ideas and concepts identified as 'important' are put forward in the group. This knowledge, in its preliminary form, was dealt with in different ways, with an array of alternatives that ranged from groups working towards shared understanding and elaborating through discussions or by them simply leaving the information unprocessed and relying on other individuals' understanding and actions (Damsa, 2014b). Until this point, the results corroborate studies of interaction and the dialogical construction of meaning-making (Atwood, Turnbull, \& Carpendale, 2010), which converge on the ideas of shared understanding being beneficial for knowledge creation and learning.

Finally, the characteristics of collaborative (inquiry) practices show that the relationship between the way students shared and materialised their knowledge into objects is a dynamic and important one. The aim, course, and content of the interactions determined how the objects evolved and developed, varying, in the two different cases, in relation to the type and degree of scaffolding provided (see Levy, 2008). The developing objects also determined the course of interactions; in the same studies, we also saw how learning activities and interactions unfolded after drafts of the objects were elaborated on and discussed. The objects passed through these different stages while also shaping the groups' ongoing interactions. The findings also show how the drafts were central in the collaborative work, and the discussions organised inquiry, shaped the activity trajectories, and determined particular courses of action. The lack of clear conceptualisations and knowledge elaboration identified in various intermediate objects led to discussing ideas, searching for additional knowledge, adjusting the focus, and revising drafts. In short, objects led the inquiries and triggered an advanced interaction with knowledge. Such a trajectory provides substantiation for the conceptualisation of the knowledge object as a sense-maker in an activity and demonstrates its potential for triggering new inquiries in educational settings (Miettinen \& Virkkunen, 2005; Miettinen \& Paavola, 2016; Damsa \& Ludvigsen, 2016).

Another aspect feeding into the conceptualisations pursued in this article concerns the way inquiry and collaboration unfolded and various activities played out during the collaborative process aimed at constructing knowledge objects. This aspect connects to the centrality of the knowledge objects in the coconstruction process as opposed to merely dialogical interaction. In short, the findings showed that at some level, when an interaction is taking place with the aim of co-constructing a shared knowledge object, the dynamics differ from those present when collaboration aims at the dialogical exploration of new meanings. Overall, important indicators of interaction that indicate an object-oriented mindset are as follows:

1. New versions of shared objects contain concepts and ideas put forward during an interaction;

2. More advanced versions and drafts that demonstrate an elaboration on new ideas and deeper understanding; and, 
Author copy

Crina Damsa \& Hanni Muukkonen (2020) Conceptualising pedagogical designs for learning through object-oriented collaboration in higher education, Research Papers in

Education, 35:1, 82-104, DOI: 10.1080/02671522.2019.1677751

3. These versions and final objects contain cumulative and joint contributions made by each of the group members.

\section{Conclusion}

This study examined design and learning activities in two higher education courses where collaborative inquiry and work with shared knowledge objects were central to the design. The findings indicate that balancing the elements of design is challenging, such as the difficulty level of the knowledge content or the complexity of project activities and students' prior knowledge and skills. As such, the study articulates the domain-specific and generic aspects of object-oriented learning and invites reflection on how the enactment of envisioned designs can be supported to enhanced students' learning experiences, as well as knowledge and competence advancement. The study provides insight into not only students' experiences and challenges in this enactment process but also the design of activities and how it takes effect during ongoing learning activities. This offers the understanding that the outcomes of learning cannot be designed, but the process and outcomes can be designed, underlining how important students' collaborative engagement is to initiating, advancing, and finalising work on knowledge objects. Ultimately, the study indicates specific aspects of design, enactment, the progression of collaboration, and the development of competencies that as a whole, allow us to advance and nuance our conceptualisations of what characterises object-oriented learning, focus future data collection, and generate research-based evidence for pedagogical practice.

\section{References}

Aditomo, A., Goodyear, P., Bliuc, A. M., \& Ellis R. (2013). Inquiry-based learning in higher education: Principal forms, educational objectives, and disciplinary variations. Studies in Higher Education, 38(9), 1239-1258. doi:10.1080/03075079.2011.616584

Bazeley, P. (2013). Qualitative data analysis. Practical strategies. London, UK: Sage Publications Ltd.

Braun, V., \& Clarke, V. (2006). Using thematic analysis in psychology. Qualitative Research in Psychology, 3(2), 77-101. doi:10.1191/1478088706qp063oa

Carvalho, L., \& Goodyear, P. (2014). The architecture of productive learning networks. New York, NY: Routledge.

Damşa, C. I., Kirschner, P. A., Andriessen, J. E. B., Erkens, G., \& Sins, P. H. M. (2010). Shared epistemic agency: An empirical study of an emergent construct. Journal of the Learning Sciences, 19(2), 143-186.

Damşa, C. I. (2014a). The multi-layered nature of small-group learning: Productive interactions in object-oriented collaboration. International Journal of Computer-Supported Collaborative Learning, 9(3), 247-281. doi:10.1007/s11412-014-9193-8

Damşa, C. I. (2014b). Shared epistemic agency and the agency of individuals, groups and communities. In J. Polman et al. (Eds.), Learning and becoming in practice, Proceedings of the International Conference of the Learning Sciences (ICLS) (Vol. 3, pp. 1283-1293). Boulder, CO: International Society of the Learning Sciences.

Damşa, C. I., \& Ludvigsen, S. R. (2016). Learning through interaction and co-construction of knowledge objects in teacher education. Learning, Culture and Social Interaction, 11, 1-18. doi:10.1016/j.lcsi.2016.03.001

Damşa, C., \& Wittek, A. L. (2019). Group work in higher education. Pedagogical designs for fostering student engagement. In M. Elken, B. Stensaker, P. Maasen, M. Nerland \& T. Proitz (Eds.), Quality work. The political, organizational and pedagogical dimensions affecting teaching and learning in higher education, Book series Higher Education Dynamics, (pp. 161-188). Dordrecht, NL: Springer Verlag.

Goodyear, P., \& Dimitriadis, Y. (2013). In medias res: Reframing design for learning. Research in Learning Technology Supplement, 21(1). doi:10.3402/rlt.v21i0.19909

Halverson, E. R., \& Sheridan, K. (2014). The maker movement in education. Harvard Educational Review, 84(4), 495-504. doi:10.17763/haer.84.4.34j1g68140382063

Hakkarainen, K. (2003). Emergence of progressive inquiry culture in computer-supported collaborative learning. Learning Environments Research, 6(2), 199-220. 
Author copy

Crina Damsa \& Hanni Muukkonen (2020) Conceptualising pedagogical designs for learning through object-oriented collaboration in higher education, Research Papers in

Education, 35:1, 82-104, DOI: 10.1080/02671522.2019.1677751

Hmelo-Silver, C. E. (2004). Problem-based learning: What and how do students learn? Educational Psychology Review, 16(3), 235-266. doi:10.1023/B:EDPR.0000034022.16470.f3

Jones, A. (2009) Re-disciplining generic attributes: The disciplinary context in focus, Studies in Higher Education, 34(1), 85-100.

Järvelä, S., Järvenoja, H., Malmberg, J., Isohätälä, J., \& Sobocinski, M. (2016). How do types of interaction and phases of self-regulated learning set a stage for collaborative engagement? Learning and Instruction, 43, 39-51. doi:10.1016/j.learninstruc.2016.01.005

Kosonen, K., Muukkonen, H., Lakkala, M., \& Paavola, S. (2012). Product development course as a pedagogical setting for multidisciplinary professional learning. In A. Moen, A. Mørch, \& S. Paavola (Eds.), Collaborative knowledge creation: Practices, tools, concepts (pp. 185-202). London, UK: Sense Publishers.

Krajcik, J., \& Blumenfeld, P. (2006). Project-based learning. In: R. K. Sawyer (Ed.), The Cambridge handbook of the learning sciences (pp. 317-334). New York, NY: Cambridge University Press.

Laakkonen, J., \& Muukkonen, H. (2019). Fostering students' collaborative learning competencies and professional conduct in the context of two gross anatomy courses in veterinary medicine. Anatomical Sciences Education, 12(2), 154-163. doi:10.1002/ase.1811

Levy, P. (2008). 'I Feel Like a Grown-up Person': First-year Undergraduates' Experiences of Inquiry and Research. Working Paper, CILASS Third Mondays Research Seminar Series, November 17, 2008. Retrieved from http://www.sheffield.ac.uk/cilass/resources/thirdmondays.html

Levy, P. (2009). Inquiry-based learning: A conceptual framework. Centre for Inquiry-Based Learning in the Arts and Social Sciences. Unpublished Manuscript, University of Sheffield, Sheffield, UK. Retrieved from http://www.sheffield.ac.uk/content/1/c6/09/37/83/CILASS\%20IBL\%20Framework\%20\%28Version\%204 $\% 29 . d o c$

Levy, P., \& Petrulis, R. (2011). How do first-year university students experience inquiry and research, and what are the implications for the practice of inquiry-based learning? Studies in Higher Education, 37(1), 85-101

Mackenzie, A. (2005). The performativity of code: Software and cultures of circulation. Theory, Culture \& Society, 22(1), 71-92.

McKenney, S., Kali, Y., Markauskaite, L., \& Voogt, J. (2015). Teacher design knowledge for technology enhanced learning: An ecological framework for investigating assets and needs. Instructional Science, 1-22. doi:10.1007/s11251-014-9337-2

Miettinen, R., \& Virkkunen, J. (2005). Epistemic objects, artefacts and organizational change. Organization, 12(3), 437-456.

Miettinen, R., \& Paavola, S. (2016). Reconceptualizing object construction: The dynamics of building information modelling in construction design. Information Systems Journal, 28(3), 516-531. doi:10.1111/isj.12125

Muukkonen, H., Lakkala, M., \& Hakkarainen, K. (2005). Technology-mediation and tutoring: How do they shape progressive inquiry discourse? The Journal of the Learning Sciences, 14(4), 527-565.

Muukkonen, H., \& Lakkala, M. (2009). Exploring metaskills of knowledge-creating inquiry in higher education. International Journal of Computer Supported Collaborative Learning, 4(2), 187-211.

Muukkonen, H., Lakkala, M., Kaistinen, J., \& Nyman, G. (2010). Knowledge creating inquiry in a distributed project management course. Research and Practice in Technology-Enhanced Learning, 5, 73-96.

Muukkonen, H., Lakkala, M. Toom, A., \& Ilomäki, L. (2017). Assessment of competences in knowledge work and object-bound collaboration during higher education courses. In: E. Kyndt, V. Donche, K. Trigwell \& S. Lindblom-Ylänne (Eds.), Higher Education Transitions: Theory and Research (pp. 288-305). London, UK: Routledge.

Muukkonen, H., Kosonen, K., Marttiin, P., Vesikivi, P., Kaistinen, J., \& Nyman, G. (2013). Pedagogical design for knowledge creating inquiry in customer projects. Knowledge Management \& E-Learning, 5(3), $278-297$.

Nerland, M., \& Jensen, K. (2010). Epistemic practices and object relations in professional work. Journal of Education and Work, 25(1), 101-120.

Paavola, S., \& Hakkarainen, K. (2005). The knowledge creation metaphor-An emergent epistemological approach to learning. Science \& Education, 14, 535-557. doi:10.1007/s11191-004-5157-0

Paavola, S., Lakkala, M., Muukkonen, H., Kosonen, K., \& Karlgren, K. (2011). The roles and uses of design principles for developing the trialogical approach on learning. Research in Learning Technology, 19(3), 233-246. 
Author copy

Crina Damsa \& Hanni Muukkonen (2020) Conceptualising pedagogical designs for learning through object-oriented collaboration in higher education, Research Papers in

Education, 35:1, 82-104, DOI: 10.1080/02671522.2019.1677751

Rheinberger, H.-J. (1997). Toward a history of epistemic things: Synthesizing proteins in the test tube. Stanford, CA: Stanford University Press.

Rogat, T. K., \& Linnenbrink-Garcia, L. (2011). Socially shared regulation in collaborative groups: An analysis of the interplay between quality of social regulation and group processes. Cognition and Instruction, 29(4), 375-415.

Sansone, N., Cesareni, D., \& Ligorio, B. (2016). The trialogical learning approach to innovate teaching. Italian Journal of Educational Technology, 24(2), 82.

Sansone, N., Cesareni, D., Ligorio, Bortolotti, B., \& Buglass, S. (2016). Teaching technology-mediated collaborative learning for trainee teachers. Technology, Pedagogy and Education, 28(3), 381-394. doi:10.1080/1475939X.2019.1623070

Spronken-Smith, R., and R. Walker. 2010. Can inquiry-based learning strengthen the links between teaching and disciplinary practice? Studies in Higher Education 35, no. 6: 723-40.

Volet, S., Summers, M., \& Thurman, J. (2009). High-level co-regulation in collaborative learning: How does it emerge and how is it sustained? Learning and Instruction, 19 (2), 128-143.

Voogt, J., H. Westbroek, H., Handelzalts, A., Walraven, A., McKenney, S., Pieters, S., \& Vries, B., (2011). Teachers learning in collaborative curriculum design, Teaching and Teacher Education, 27 (2011) 1235-1244, doi:10.1016/j.tate.2011.07.003

Säljö, R. (2010). Digital tools and challenges to institutional traditions of learning: Technologies, social memory and the performative nature of learning. Journal of Computer Assisted Learning, 26, 53-64.

Yin, R. K. (2013). Case study research, design and methods (4rd ed.). Newbury Park, CA: Sage 